\title{
A colaboração entre professoras como prática de formação para ensinar matemática nos anos iniciais
}

\author{
Collaboration as a practice in teacher education to teach \\ mathematics in primary school
}

\author{
Adair Mendes NACARATO' \\ Kátia Gabriela MOREIRA²
}

\begin{abstract}
Resumo
Este artigo discute o papel da colaboração nos processos de apropriação dos modos de aprender e ensinar matemática nos anos iniciais, apoiando-se na perspectiva histórico-cultural. Toma como objeto de análise o caso da professora Maria, que estabeleceu parceria com outras duas professoras, em momentos diferentes. A pesquisa foi desenvolvida no contexto do Programa Observatório da Educação (OBEDUC). Os dados são constituídos de excertos extraídos da dissertaçáo de mestrado de Maria, de narrativas produzidas por ela, de relatórios e transcrições dos encontros do grupo OBEDUC. A análise centra-se nos indícios de aprendizagem de Maria.
\end{abstract}

Palavras-chave: Programa Observatório da Educação. Perspectiva histórico-cultural. Matemática nos anos iniciais. Práticas colaborativas de formação docente.
Abstract

This article discusses the role of collaboration in the processes of appropriation of the ways of learning and teaching mathematics in primary school, based on the historical-cultural perspective. It takes as object of analysis the case of the teacher Maria, who established a partnership with two other teachers, at different times. The research was developed in the context of the Education Observatory Program (OBEDUC). The data include excerpts extracted from Maria's master's thesis, narratives produced by her, reports and transcripts of the meetings of the OBEDUC group. The analysis focuses on the learning evidence produced by Maria.

Keywords: Educational Observatory Program. Historical-cultural perspective. Mathematics in primary school. Collaborative practices in teacher education.

1 Graduada em Matemática pela Pontifícia Universidade Católica de Campinas (1975), mestre em Educação pela Universidade Estadual de Campinas (1994) e doutora em Educação pela Universidade Estadual de Campinas (2000). Atualmente é docente da Universidade São Francisco, campus de Itatiba, junto ao Programa de Pós-Graduação Stricto Sensu em Educação e ao curso de Pedagogia. É editora da Revista Horizontes. É pesquisadora produtividade/CNPq, nível 2. É líder dos grupos de pesquisa: Grupo Colaborativo em Matemática (Grucomat) e Histórias de Professores que Ensinam Matemática (HIFOPEM). E-mail: adamn@terra.com.br.

2 Doutoranda do Programa de Pós-Graduação Stricto Sensu em Educação da Universidade São Francisco. Mestre em Educação Pela Universidade São Francisco (2015), na linha de pesquisa Educação, Sociedade e Processos Formativos. Licenciada em Pedagogia pela Universidade São Francisco (2010). Participa do Grupo Colaborativo em Matemática (Grucomat) na Universidade São Francisco, Itatiba - SP, ampliando discussōes e produçóes no campo da Matemática e do processo de ensino e aprendizagem. Professora dos anos iniciais da rede municipal de ensino de Nazaré Paulista. E-mail: ktiagabriela@hotmail.com.

\begin{tabular}{|l|l|l|l|l|l} 
R. Educ. Públ. & Cuiabá & v. 28 & n. 69 & p. $767-791$ & set./dez. 2019
\end{tabular}




\section{Introdução}

A formação de professores tem sido foco de políticas públicas e de investigaçóes; raro é o programa de pós-graduação no Brasil que não tenha a linha de pesquisa em formação docente. Muito já se discutiu sobre os modelos de formação docente, principalmente a continuada - nosso foco no presente artigo. Pesquisas como as de Gatti e Barretto (2009), Gatti, Barretto e André (2011) e André (2011), ao realizarem mapeamentos e análises de projetos e programas - sejam eles de políticas públicas, sejam de pesquisas acadêmicas -, nos sinalizam que muito se avançou em termos de concepçóes de formação docente mais alinhadas com o pensamento do professor, escutando-o em suas necessidades e propondo outros modelos de formação que rompam com o tecnicismo e a racionalidade técnica, tâo marcantes nas últimas décadas do século XX. Como afirma Nóvoa (2009, p. 12, grifos do autor): "Os professores reaparecem, neste início do século XXI, como elementos insubstituíveis não só na promoção das aprendizagens, mas também na construçấo de processos de inclusão que respondam aos desafios da diversidade e no desenvolvimento de métodos apropriados de utilização das novas tecnologias". No entanto, como afirma Nacarato (2016), ainda há um distanciamento entre as perspectivas para a formação docente apontadas pelas pesquisas e a elaboração de políticas públicas para tal formação.

Igualmente complexa é a formação do professor que ensina matemática nos anos iniciais do ensino fundamental. Ele geralmente é formado em curso de Pedagogia, com reduzida carga horária voltada aos conteúdos específicos que compóem o currículo da escola básica. Essa formação lacunar requer que esse profissional esteja em constante participação em projetos de formação continuada, visando a superar tais lacunas. No entanto, nossa vivência como formadora e professora tem nos mostrado que os diferentes sistemas de ensino - municipal ou estadual - não têm dado conta de oferecer projetos que atendam às necessidades dos professores; ou, se oferecem contextos formativos, esses são, na maioria das vezes, marcados pela racionalidade técnica, ou seja, com o foco centrado na oferta de "receitas" para a sala de aula e propostas externas à prática dos professores. Concordamos com Gatti e Barretto (2009, p. 201-201):

Outra razão comumente invocada nos estudos críticos sobre formação continuada é a limitada, senão ausente, participação dos professores na definição de políticas de formação docente, como categoria profissional, e na formulação de projetos que têm a escola e o seu fazer pedagógico como centro. Nestas condiçôes, eles não se envolvem, não se apropriam dos princípios, não se sentem 
estimulados a alterar sua prática, mediante a construção de alternativas de ação, ao mesmo tempo em que se recusam a agir como meros executores de propostas externas.

Acrescente-se a isso a pressão que esses profissionais sofrem nas respectivas escolas em razão das demandas relativas às avaliações externas, as quais, muitas vezes, diante dos baixos desempenhos dos alunos nessas provas, retiram do professor seu objetivo principal, que é proporcionar a seus alunos uma formação adequada. Muitos professores acabam por colocar o foco de suas aulas na preparação dos alunos para realização dessas provas.

Acreditando fortemente nos modelos de formação continuada pautados na colaboração e no compartilhamento de práticas, temos buscado romper com os modelos postos e investir em práticas formativas que se contraponham à perspectiva apontada por Gatti e Barretto (2009) como limitadora do desenvolvimento docente. Dentre os diferentes espaços formativos que temos criado no interior da nossa universidade, um deles está relacionado ao Programa Observatório da Educação. O projeto do Observatório da Educação (OBEDUC, 2013-2016), intitulado "Estudos e pesquisas e de letramento matemático escolar e de formaçấo docente", busca investigar, por meio de um trabalho colaborativo com professores da educação básica, as práticas de letramento - mais especificamente, o letramento matemático escolar -, bem como as práticas de formação docente de professores que ensinam matemática.

$\mathrm{O}$ trabalho aqui apresentado foi desenvolvido nesse contexto. Nosso objetivo neste texto é apontar indícios de aprendizagens de professoras participantes do OBEDUC, a partir de parcerias estabelecidas com mestrandas. Apontamos como os processos de significaçóes que perpassaram a sala de aula possibilitaram aprendizagens não apenas dos alunos, mas, principalmente, das professoras.

O texto está organizado em quatro seçóes. Inicialmente apresentamos o contexto da pesquisa; em seguida, algumas reflexóes sobre nossa compreensão da aprendizagem docente na perspectiva histórico-cultural; expomos a análise dos contextos vividos pelas duas duplas; e, finalmente, nossas consideraçóes sobre os processos formativos decorrentes das parcerias que são estabelecidas em grupos de trabalho colaborativo.

\section{O contexto da pesquisa}

A dinâmica do trabalho colaborativo no nosso projeto OBEDUC decorre de nossas aprendizagens como formadoras, numa postura de respeito aos saberes dos professores. Esses foram os cuidados que a coordenação do projeto teve desde a sua implantação na composição do grupo - é importante destacar que assumimos 
a coordenação do projeto em seu $3^{\circ}$ ano (a partir de 2015). Houve algumas mudanças desde o seu início, mas basicamente ele é composto por professoras de escolas públicas (sete até 2015 e seis, a partir de 2016) que atuam no ciclo de alfabetização ( $1^{\circ}$ ao $3^{\circ}$ ano); quatro mestrandas (duas delas concluíram suas dissertaçôes no início de 2015 e duas no início de 2017); uma doutoranda do Programa de Pós-Graduação Stricto Sensu em Educação; e, atualmente, quatro docentes da universidade.

O grupo se reúne quinzenalmente para estudar e compartilhar as narrativas de prática de sala de aula - geralmente uma sequência de tarefas com vistas a um conteúdo específico - produzidas mensalmente pelas professoras. Essas tarefas, na maioria das vezes, decorrem dos estudos que o grupo realiza. As narrativas são enviadas a todas as participantes, que fazem leitura prévia e, no dia do encontro destinado ao compartilhamento, há discussóes e reflexóes sobre o texto produzido.

Das quatro mestrandas do Programa, três estabeleceram parcerias com as professoras para realização de suas pesquisas. Uma delas, a Maria, cujo caso aqui tomamos como objeto de análise, participou do OBEDUC nos anos 2013-2014 como mestranda e, em 2015-2016, como professora da escola básica, atuando no ciclo de alfabetizaçáo. Na primeira etapa, ela estabeleceu parceria com a professora Lia para desenvolver a pesquisa; na segunda etapa, ela foi a professora parceira de outra mestranda, Camila, em sua turma de $3^{\circ}$ ano.

Nessas duas parcerias, as professoras envolvidas produziram suas narrativas, seus relatórios de pesquisa, bem como uma dissertaçáo de mestrado. Os dados aqui analisados foram extraídos das narrativas, de transcriçóes dos encontros do grupo OBEDUC, dos relatórios anuais, bem como da dissertação de mestrado de Maria.

Nesse material, buscamos, numa perspectiva histórico-cultural, as significaçóes que foram produzidas e que nos apontam indícios de aprendizagens docentes. Apoiando-nos em Freitas (2009, p. 4), consideramos que, na perspectiva vigotskiana (Vigotski foi o maior representante da teoria histórico-cultural), "a pesquisa visa compreender os eventos investigados descrevendo-os, mas procura também suas possíveis relaçóes, integrando o individual com o social, focalizando o acontecimento nas suas mais essenciais e prováveis relaçóes”. A autora complementa:

O pesquisador tem possibilidades de aprender, se transformar e se ressignificar durante o processo de pesquisa. O mesmo acontece com o pesquisado, que náo sendo coisa mas sujeito, tem também oportunidade de refletir, aprender e se transformar no decorrer da pesquisa. Pesquisador e pesquisados, como diz Amorim (2006), ao participarem do evento da pesquisa se tornam produtores de textos. O texto 
do pesquisador não deve emudecer o do pesquisado mas lhe restituir as condiçóes de enunciação e circulação que lhe conferem múltiplas possibilidades de sentido. (FREITAS, 2009, p. 5)

Ainda, coerentemente com a perspectiva histórico-cultural, buscamos por indícios de aprendizagens. Para isso, nos apoiamos em Góes (2000, p.19), que, no âmbito dessa teoria, considera que, no paradigma indiciário, há valorização do singular, visto que as pesquisas se voltam para "casos individuais, que devem ser reconstruídos, compreendidos por meio de sinais, signos, pistas, indícios ou sintomas. Mas decifrar e ler pistas é estabelecer elos coerentes entre eventos e, por isso, o componente narrativo faz parte das interpretaçóes indiciárias". Assim, não se abandona a ideia de totalidade, mas centra-se na busca de interconexóes que permitem compreender, na singularidade, a totalidade.

No caso específico desta pesquisa, tanto as pesquisadoras quanto as professoras são participantes do grupo OBEDUC, portanto, já trazem apropriaçóes do que seja o trabalho de parceria, o trabalho colaborativo. Além disso, a perspectiva histórico-cultural é tomada como nosso referencial teórico para discussão do desenvolvimento humano e dos processos de aprendizagens docentes.

\section{Desenvolvimento e aprendizagem docente}

Reafirmamos que nossa concepção de formação docente se pauta no reconhecimento do professor como protagonista de sua prática, e essa prática precisa ser conhecida, problematizada, valorizada e (re)significada. Para isso, nossa perspectiva de formação sempre se baseia na constituição de grupos com dimensão colaborativa. É assim que concebemos o grupo OBEDUC.

Por trás dessa concepção há a compreensão dos processos de constituição do sujeito e dos modos como ocorrem suas aprendizagens. Defendemos que a aprendizagem do professor náo pode ser analisada sob a mesma perspectiva da aprendizagem da criança. Ainda são recentes na literatura, na perspectiva histórico-cultural, e, principalmente, em Educação Matemática, estudos que abordem a aprendizagem do adulto professor. Aprendizagem e desenvolvimento são termos indissociáveis; a discussão de um remete, necessariamente, à do outro. Partiremos da premissa de que toda aprendizagem resulta em desenvolvimento. Mas o que dizer do desenvolvimento do adulto?

Mayen (2012), por exemplo, considera que o desenvolvimento de adultos é uma questão ainda iniciante, pois há poucas fontes para responder a essa questão. Para esse autor, o conceito de apropriação de situaçôes pode ser um caminho para 
tal discussão. "Em numerosos trabalhos de inspiração vygotskiana, os processos de apropriaçáo referem-se aos artefatos (objetos, instrumentos, signos e sistemas de signos, normas, leis e regras que compóem o que Lucien Sève chamou de 'o mundo humano')" (MAYEN, 2012, p. 290, grifos do autor).

Há, nessa perspectiva, dois conceitos em jogo: apropriação e situação, para os quais nos apoiaremos em Mayen (2012) e Smolka (2000) em nossas reflexóes. Mayen (2012) não discute o conceito de apropriação, nem analisa, necessariamente, o desenvolvimento do adulto professor; no entanto, suas análises ajudam-nos na compreensão do nosso objeto de estudo. Smolka (2000), de forma similar, nos auxilia na reflexão do conceito de apropriação. Essa autora discute os diversos modos como o termo "apropriação" tem sido utilizado em diferentes abordagens teóricas. Para o nosso estudo, importam-nos suas sínteses. Para ela, a questão da apropriação precisa ser discutida relacionada ao problema da significação. "Esse deslocamento encontra-se ancorado na concepção de mediação do signo no desenvolvimento humano, na centralidade e no estatuto teórico do signo na teoria vygotskyana" (SMOLKA, 2000, p.29). Alicerçada nas ideias de Vygotsky, a autora reafirma: "Não é o que o indivíduo é, a priori, o que explica seus modos de se relacionar com os outros, mas são as relaçóes sociais nas quais ele está envolvido que podem explicar seus modos de ser, de agir, de pensar, de relacionar-se" (p. 30, grifo da autora). Ou, ainda, "Eu me relaciono (e narro) para mim mesmo como as pessoas se relacionam comigo (e narram para mim) [...][...] Eu sou uma relaçáo social comigo mesmo" (VYGOTSKY, 1989 apud SMOLKA, 2000, p. 31). Trata-se, segundo a autora, de compreensão do processo de formação do funcionamento mental das relações sociais, o qual só pode ser compreendido quando se considera

a produção simultânea de signos e sentidos, relacionada à constituiçáo de sujeitos, na dinâmica dessas (inter)relaçôes. Como sujeitos, os indivíduos são afetados, de diferentes modos, pelas muitas formas de produçáo nas quais eles participam, também de diferentes maneiras. Ou seja, os sujeitos são profundamente afetados por signos e sentidos produzidos nas (e na história das) relaçóes com os outros. (SMOLKA, 2000, p. 31)

É na teia das relaçóes que o sujeito se constitui, produz significações e apropriaçóes. No entanto,

a apropriação não é tanto uma questáo de posse, de propriedade, ou mesmo de domínio, individualmente alcançados, mas 
é essencialmente uma questão de pertencer e participar nas práticas sociais. Nessas práticas, o sujeito - ele próprio um signo, interpretado e interpretante em relação ao outro - não existe antes ou independente do outro, do signo, mas se faz, se constitui nas relaçóes significativas. (SMOLKA, 2000, p. 37)

No caso específico deste trabalho, essas práticas dizem respeito à profissão docente e aos espaços de formaçáo pelos quais passam os professores. Portanto, os signos que se interpenetram nas discussóes - seja na sala de aula, seja no grupo OBEDUC - produzem sentidos, são apropriados pelos sujeitos. Assim, Smolka (2000, p. 38) nos alerta que não há possibilidades de posse, porque

se signos e sentidos são sempre produzidos por sujeitos em relação, os muitos modos de ação e interpretação desenvolvidos (no tornar próprio, no atribuir pertença, no tornar pertinente, no adequar, no transformar...) são parte de uma prática historicamente construída, de uma trama complexa de significaçóes nas quais eles participam sem serem, contudo, capazes de controlar a produção, de reterem ou de se apropriarem dos múltiplos, possíveis e contraditórios sentidos (que vão sendo) produzidos...

Portanto, o desenvolvimento do professor é um processo, nem sempre controlável, nem sempre linear. As situaçôes as quais vivencia vão lhe possibilitando essa produção de significaçóes, de apropriações.

Para Mayen (2012, p. 291):

As situaçóes sociais e profissionais são o produto de construçóes e evoluçóes históricas. Elas são dadas, propostas, impostas, mais ou menos abertas ou reservadas. Tanto como formas sociais, e com as quais as pessoas têm que fazer, das quais elas se ocupam, com as quais elas devem fazer para poder responder às necessidades, aos desejos, às aspiraçôes.

Elas sempre se constituem em potencial de desenvolvimento.

Uma situação é um artefato e um ambiente específico que dá um certo lugar, função e significação aos artefatos que a compóem e aos artefatos em ação que exigem as funçôes adequadas à situação: objetos, maneiras de fazer, jogos de linguagem, modos de raciocínio, conceitos, etc. (MAYEN, 2012, p. 304) 
Esse autor apoia-se na ideia de Vygotsky de que na situação de desenvolvimento há os períodos críticos, nos quais há uma transformação rápida ou profunda do funcionamento mental e social. Assim, Mayen (2012) denomina "situaçóes potenciais de desenvolvimento" aquelas segundo as quais esse período crítico se manifesta na dinâmica da vida profissional de uma pessoa. Para nós, os contextos de trabalho colaborativo podem se constituir em situaçóes potenciais de desenvolvimento, desde que os professores se tornem suscetíveis aos processos de formação, produzam significaçóes para os discursos e as práticas compartilhadas e se apropriem dos modos de ensinar matemática. No entanto, sabemos que nem todos os professores que participam dos mesmos processos se apropriam da mesma forma das situaçóes e se desenvolvem igualmente. Como afirma Mayen (2012, p. 298), "a qualidade da experiência que cada pessoa faz das situaçóes pode diferir profundamente daquelas de outras pessoas".

Nas situaçôes cotidianas que o professor vive no contexto escolar ou nos espaços formativos aos quais pertence, ele vai adquirindo um saber da experiência, tal como postula Contreras Domingo (2013); ou seja, um conhecimento sobre a prática educativa, as formas de viver nesses contextos e interagir com os diferentes atores. Para ele, esse saber tem

otros ingredientes, otros modos de saber (que involucran lo personal y lo situacional, el encuentro y las relaciones subjetivas cambiantes, lo inesperado y lo situacional, el encuentro y las relaciones subjetivas cambiantes, lo inesperado, lo ambiguo y lo incierto, etc.) que se ponen en juego, y que este saber, este modo de saber, no es la misma naturaleza que el saber disciplinar. (CONTRERAS DOMINGO, 2013, p. 127)

Trata-se de um saber singular, pois a experiência é única, mas é um "saber sedimentado en lo vivido, y que proporciona un bagaje y una orientación para la acción, sin embargo, es un saber siempre naciente, un saber siempre en renovación, y que revela una cualidad esencial del saber pedagógico necesario" (p. 129).

O docente, em sua trajetória profissional, circula por diferentes espaços, os quais podem ou não ser contextos formativos. Aqui nossa ênfase é para o movimento entre grupo-sala de aula-grupo. Defendemos que, num grupo de dimensão colaborativa, um dos aspectos centrais é o respeito pelo outro, pela sua singularidade, pelo tempo que necessita para se apropriar e (re)significar as práticas compartilhadas, vivenciar experiências e se desenvolver profissionalmente. Há o pressuposto de que se aprende com o outro, "no encontro dialógico entre dois sujeitos que intercambiam enunciados, buscam respostas, resistem, argumentam" 
(FREITAS, 2009, p. 5). O compartilhamento das narrativas de práticas no contexto do grupo OBEDUC tem possibilitado que todas as participantes se apropriem das situaçóes narradas - dos modos de organizar a turma, dos conceitos matemáticos que circulam nos contextos de sala de aula, nos modos de produzir conhecimentos escolares, enfim, do modo de ser e se constituir professora que ensina matemática nos anos iniciais. Nesse movimento, cada uma vai construindo seus saberes da experiência e vai aprendendo modos de ensinar matemática às crianças em início de escolarização.

Nosso foco neste texto serão as aprendizagens das três professoras envolvidas nas parcerias, com maior centralidade nas aprendizagens de Maria, até porque, como analisaremos na próxima seção, ao ter a pesquisa como eixo de sua formação, ela se apropriou de modos de registro e análise dos episódios em sala de aula, trazendo indícios de constituição profissional como pesquisadora e, ao longo de 2015 e 2016, pudemos acompanhar como as suas apropriaçóes se revelaram na sua prática narrada no grupo.

\section{Parcerias potencializadoras de aprendizagens docentes}

Há no grupo OBEDUC um rico ambiente de práticas compartilhadas que produzem (re)significaçôes do que seja ensinar e aprender matemática. As sessóes de estudo sempre instigam as professoras a elaborarem sequências de tarefas para suas salas de aula, com o objetivo de analisar como ocorre o processo de elaboração conceitual dos alunos. Muitas vezes, as professoras ainda se encontram em processo de elaboração conceitual em matemática, em decorrência da formação lacunar que tiveram nas suas formaçóes iniciais; ao compartilharem suas dúvidas no grupo, há a colaboração dos pares no sentido de contribuir para a superação das dificuldades. O grupo tem se revelado um espaço de formação, pois, sentindose respeitadas em suas dúvidas, elas as expressam com tranquilidade, pois sabem que terão ajuda das colegas.

Comojáanunciamos, a professora Maria assumiu um duplo papel: inicialmente atuou no grupo como pesquisadora (embora tenha continuado atuando como professora) e, para isso, estabeleceu parceria com a professora Lia, do $1^{\circ}$ ano, em 2013. Nesse ano - início do projeto OBEDUC - as professoras do $1^{\circ}$ e do $2^{\circ}$ anos estabeleciam uma parceria no grupo, com o objetivo de elaborar algumas tarefas para a sala de aula; outras tarefas eram elaboradas individualmente pelas próprias professoras e compartilhadas por meio de suas narrativas. Nesse movimento, muitas ideias desenvolvidas por uma das professoras eram incorporadas nas práticas de outras. 
A pesquisa de Maria teve como objetivo investigar como as crianças do $1^{\circ}$ ano do Ensino Fundamental produzem significados matemáticos, quando inseridas em práticas de letramento matemático escolar com foco em resolução de problemas. Ela também visou analisar a comunicação oral e escrita, bem como as potencialidades de ferramentas pedagógicas para a produção de significados matemáticos. Para isso, ela não apenas estabeleceu a parceria com a professora Lia, como acompanhou a turma ao longo de 2013. No ano de 2014, ela cuidou da organização e da análise dos dados e defendeu sua dissertação em fevereiro de 2015.

O momento de análise foi muito rico e reflexivo para Maria, pois, por meio do estudo e do confronto das ideias dos autores com os dados produzidos, ela buscou olhar para esses dados e construir significaçóes para o processo vivido. Dentre as situaçóes por ela analisadas, destacaremos duas para discussão neste texto, visto que identificamos indícios de suas aprendizagens nesse processo nos anos de 2014 e 2015: o uso de ferramentas pedagógicas e a resolução de problemas em sala de aula.

No que diz respeito às ferramentas pedagógicas e, em especial, aos materiais manipulativos, assim se manifestou a pesquisadora:

Destacamos a necessidade de se ensinar a usar o material uma vez que é função da escola o ensino da utilização de determinados materiais. No entanto, quando partimos de uma concepção de resolução de problemas, tomamos como caminho o ensino através de problematizaçóes; há que se considerar a natureza das problematizaçôes, uma vez que as mesmas devem manter o foco nos objetivos do uso do material, bem como no isomorfismo que o uso do mesmo possibilita com o conceito a ser trabalhado. Além disso, há que se considerar que a relaçáo do aluno com o material pode não corresponder a uma relação esperada pelo professor, o que lhe cabe o cuidado e a percepção do sentido atribuído pelo aluno e, a partir disso, realizar problematizaçôes. (MOREIRA, 2015, p.93)

Tais reflexões foram produzidas na finalização de sua dissertação. No entanto, mobilizaram o grupo OBEDUC para discutir o papel do material manipulável nas primeiras reunióes de 2015. Nesse excerto destaca-se a compreensão da pesquisadora quanto à função do material manipulativo como ferramenta mediadora do processo de elaboraçáo conceitual; nesse processo, o professor tem papel central, visto que os conceitos não estão no material, mas nas relaçóes estabelecidas a partir deles. 
Mas quais as implicaçóes dessas constatações para a prática da pesquisadora? Mesmo durante a pesquisa, Maria atuava como professora, mas não tinha $\mathrm{o}$ hábito de registrar sua prática. Como mestranda no grupo, acompanhava os registros das professoras, porém não produzia o seu próprio. Quando concluiu a sua dissertação e assumiu apenas o papel de professora do OBEDUC, ela passou a adotar essa prática. Provavelmente ela já tivesse incorporado, nesses dois anos de acompanhamento do grupo, a importância desse registro e, ao adotálo sistematicamente, validou esse procedimento. Assim se declarou num dos encontros do grupo:

[...] agora na questão da geometria, eu me envergonho do que eu fui ano passado, gente, como que eu trabalhei dessa forma ano passado, mas como? Porque no ano passado eu não tinha essa prática de registrar, trazer para o grupo, para discutir. [...] Eu atribuo essa mudança e todo esse resultado que eu obtive, por conta de todo o processo de registrar. Então a cada tarefa, eu escrevia a narrativa e trazia para o grupo e vocês falavam: "está tudo certo". E ai eu voltava para a sala pensando nessas coisas. Para mim, era muito conflituoso, pensar em geometria, voltar a estudar geometria, porque foi necessário, muita coisa eu não sabia mais e nem sei se tinha aprendido. [...] A gente [ela $\mathrm{e}$ seus alunos] construiu, a gente discutiu, a gente fez massinhas, teve histórias, eu trouxe narrativas... [...] Eu acho que eu consegui, mesmo que um pouquinho, eu consegui trazer uma geometria com sentido para os meus alunos. (Maria, encontro, 9 dez. 2015)

Nesse excerto a professora reflete sobre sua formação lacunar na área de geometria - esse foi o foco de estudo do grupo em 2015 - e sobre o modo como ela conseguiu se superar, por meio da prática, aprendendo com os estudos, com o grupo e com seus alunos. Sua ênfase é posta no registro, em como ele possibilita a quem registra tomar consciência do que fez, pois, no ato da escrita, o autor precisa refletir sobre suas ações para transmiti-las ao leitor. Ainda, com relação ao papel do registro, ela assim se manifesta:

Outra evidência da pesquisa foi com relação ao registro. Quando nos debruçamos para a análise dos registros dos alunos, constatamos o quanto os problemas que propusemos, em sua maioria, eram simples e estavam aquém da capacidade de resoluçáo deles. Portanto, o material manipulativo ou a reta numérica não fazia sentido para 
eles. Daí o papel da pesquisa. Foi por meio dela que fomos afunilando teoricamente o nosso olhar para os registros dos alunos. Por outro lado, quando os alunos se viram diante do contexto de elaborar problemas, foi possível constatar o avanço deles, quantas ideias eles trouxeram para a elaboração do texto, revelando a apropriaçáo do gênero textual de problema, bem como evidenciando que se apropriaram dos elementos que compóem esse texto. Assim, ressaltamos que o registro não apenas possibilita a reflexão do aluno no ato de sua produção, mas também revela ao professor o quanto a tarefa trabalhada foi ou não significativa para o grupo. (MOREIRA, 2015, p. 144)

Registrar a prática, por meio de narrativas, tem sido uma das ênfases do nosso projeto, pois o registro se constitui numa prática de letramento docente, na produção de um conhecimento da prática (CHOCHRAN-SMITH; LYTLE, 1999), ou seja, um conhecimento local, refletido, com sentido e decorrente das apropriações feitas pela professora. A produção de narrativas tem sido por nós considerada como prática de pesquisa do professor, além de ser autoformativa.

No que diz respeito ao uso de materiais manipulativos, destacamos uma das narrativas de Maria na qual ela aborda o uso do material Cuisenaire.

A contagem até o 10, o reconhecimento dos números e a escrita dos mesmos tem muita força nas práticas do início do processo de escolarização das crianças. Entendo que não poderia ser diferente, visto que são habilidades numéricas básicas para que as crianças possam estabelecer outras relaçóes. No entanto, um desafio para mim era pensar em como ajudar as crianças a construírem novas relaçóes. Como possibilitar o avanço das ideias das crianças com relação aos números, tendo como foco uma aprendizagem significativa? Quais tarefas que possibilitariam às crianças o estabelecimento de novas relaçôes numéricas? [...] Diante desse contexto, optei por desenvolver um trabalho com a composição do número 10 com meus alunos, fazendo uso do material manipulativo Cuisenaire. (Maria, narrativa, abr. 2016)

No excerto identificamos o reconhecimento, pela professora, da importância do conteúdo a ser trabalhado com seus alunos e sua preocupaçáo com uma proposta de trabalho que fosse significativa para eles e oportunizasse estabelecer novas relaçôes referentes à composição do número 10. Partindo dessa 
preocupação, a professora lançou mão de uma sequência de tarefas, partindo do material manipulativo. Na perspectiva teórica por nós adotada, a intencionalidade pedagógica do professor é fundamental, há uma centralidade no papel da escola como agência promotora de aprendizagens e desenvolvimento humano.

A escolha do material aponta para o reconhecimento da potencialidade da sua utilização como uma ferramenta pedagógica mediadora, capaz de auxiliar as aprendizagens matemáticas dos alunos. A mobilização do professor diante do uso de materiais manipulativos em suas aulas ocorre a partir do momento em que ele vê sentido na sua utilização. Nesse contexto de análise, entendemos que a entáo professora se apropriou de sua experiência enquanto pesquisadora e incorporou à sua prática o uso do material manipulativo, com o objetivo de fornecer aos alunos uma aprendizagem com significaçôes do conceito de número. Tal fato se evidenciou quando Maria, ao concluir sua narrativa, manifestou:

Acredito que a sequência utilizando o material Cuisenaire possibilitou aos alunos o estabelecimento de relaçóes importantes para o desenvolvimento do senso numérico. E de modo específico, contribuiu significativamente para o reconhecimento das possibilidades de se formar o número 10. É certo que ainda há que se pensar em outras oportunidades para as crianças estarem em contato com essas ideias, porém, percebo que todo o movimento de construção realizado junto com as crianças foi muito importante. (Maria, narrativa, abr. 2016)

Outra reflexão que ela produziu em sua dissertação foi com relação à resolução de problemas, que era o foco principal de sua pesquisa. Após analisar episódios da sala de aula de Lia, ela assim se manifestou em seu texto:

As análises das tarefas frente à resolução de problemas, sobretudo, ao entendimento acerca do texto da situação-problema, como um passo inicial para a resolução, nos apontaram alguns caminhos indispensáveis para um trabalho que priorize a compreensão nas aulas de matemática. Primeiramente, destacamos as práticas de alfabetizaçáo matemática na perspectiva do letramento que visaram um trabalho sistemático frente à leitura e à significação do texto da situação-problema. As análises nos apontam que a existência de um trabalho específico com o texto do problema possibilita aos alunos uma maior facilidade na leitura e compreensáo dos textos matemáticos, principalmente, dos textos de situaçóes-problema. 
A reflexão acerca da estrutura do texto, sua linguagem, os conceitos envolvidos, o uso de termos específicos e as significaçóes que os alunos atribuem ao mesmo, evidenciaramse fundamentais para o processo de resolução de problemas, sobretudo, para essas crianças que estáo iniciando o contato com esses textos. (MOREIRA, 2015, p. 113)

E a pesquisadora continua:

Concluímos que a oralidade se evidencia um instrumento poderoso para a apropriação da linguagem, bem como a atribuição de significados. Deste modo, entendemos que, para a perspectiva de trabalho que adotamos, náo há como conceber uma sala de aula em que silêncio é considerado uma potente ferramenta de concentração, atenção e até mesmo de pensamento... pelo contrário, buscamos cada vez mais a participação dos alunos por meio de verbalizaçóes de ideias, levantamento de hipóteses e pensamentos, sobretudo, num $1^{\circ}$ Ano do Ensino Fundamental em que a oralidade é um instrumento mais frequente e natural. Para isso, há que se dedicar na busca por tarefas que priorizem a oralidade como forma de circulação de significados que possibilitarão a apropriação conceitual por parte dos alunos. (MOREIRA, 2015, p. 115)

Essas reflexóes de Maria remetem-nos para as considerações de Roxo (2010, p. 54) sobre as

relaçóes entre a oralidade e escrita no letramento. Mais exatamente, trata-se de determinar não só a descrição do papel constitutivo da interação social (em seu caráter oral) para o uso e o conhecimento desenvolvido pela criança sobre o objeto escrito, mas também com quais relaçóes entre as modalidades oral e escrita do discurso nos defrontamos aí.

Imersas que estávamos, nesses momentos, nas discussóes sobre práticas de letramento, Maria trouxe indícios de aprendizagem desses diferentes componentes do letramento. Em outros momentos por ela narrados, ao longo de 2015 e 2016, identificamos a valorização dada por ela para o discurso oral em sala de aula. Destacamos o excerto de uma de suas narrativas que apresenta os movimentos de uma tarefa de classificação dos sólidos, na qual a professora permite o movimento de oralidade em sala de aula: 
Eles também perceberam que existiam dois grupos: o grupo dos sólidos que rolavam e o grupo dos sólidos que não rolavam. No entanto, acreditavam que os dois prismas também faziam parte dos sólidos que rolavam. Tal constatação veio mediante a exploração dos sólidos geométricos no cháo e, nessa exploração, acabaram colocando força e lançaram os objetos, o que fez com que os prismas, de fato, rolassem. Náo pelo movimento de si próprio no chão, mas pela força colocada no mesmo. Sendo assim, destaco a discussáo desse grupo no momento da socialização:

Ana: Prô, aquele lá não pode ficar junto com aqueles que eles colocaram!

Paula: A gente sabe!

P: Como assim, Ana? Você está falando dos prismas?

Ana: É!

P: Ok. Vamos ver... Na solução dos colegas, existem dois grupos. Isso está de acordo com o que a prô pediu. Certo?

Pedro: Só que os dois prismas tá separado.

P: Como assim?

Pedro: Ele está separado... As pontinhas não podem ficar ali. P: Ok. Mas o que o seu grupo pensou que é diferente do que eles apresentaram?

Pedro: A gente pensou primeiro... Não tem esses dois amarelos? (cilindro e cone) Entäo! A gente colocou eles. Depois a esfera, ai ficou igualzinho. Os três rolam!

P: Mais alguém quer comentar o que esse grupo pensou?

Lucas: Eu acho que eles pensaram que o prisma dá pra rolar também... Colocando força.

Talita: Mas...Não! Colocando força ele não rola!

Felipe: $O$ prô, mas a esfera e o cone é só encostar que ele rola. João: É nem precisa jogar forte. É só colocar, porque eu coloquei lá fora e ele rolou. E também toda hora que a Paula colocava eles rolavam.

Júlia: E também, prô, tem a forma dele que é diferente. Esse tem ponta (prisma) e esses não (não poliedros).

Talita: Prô, não tem arestas também!

P: Agora vamos deixar o grupo defender sua ideia!

Luiz: É assim, o prisma a gente fez o teste lá. Ele roda, sim. Lucas: Não rola.

Luiz: Eu fiz com pouca força! Olha... (joga o prisma no chão e ele fica parado, depois tenta novamente).

Ana: Está colocando força e mesmo assim nem saiu do lugar. 
Luiz: É, mas a gente fez lá fora (irritado).

P: O que aconteceu, Luiz?

Luiz: Depende do piso. Eu fiz lá fora!

P: $E$ aí, turma? O que vocês acham?

Lucas: $O$ prô, os amarelos nem precisa colocar força que eles rolam.

P: Epor que isso acontece?

Lucas: Porque ele tem a forma arredondada!

Júlia E também não tem ponta!

P: Mas o cone tem ponta!

Ana: Só tem uma.

João: Mas a lateral é redonda.

P: E o grupo, o que está achando?

Luiz: O prisma rola, eu fiz três vezes lá fora. (Maria, narrativa, maio 2015)

Esse excerto, embora longo, mostra o movimento no qual Maria coloca seus alunos para analisarem suas ideias e as dos colegas; para argumentarem e se contraporem - enfim, para produzirem significaçóes para o processo de elaboração conceitual, num processo dialógico. Constatamos que, após o grupo manifestar a solução da proposta estabelecida pela professora, recebeu a posição dos colegas da turma, que manifestaram suas ideias e os argumentos contrários à solução encontrada por eles. Nesse movimento, percebemos o estabelecimento de uma esfera de argumentação matemática em torno da solução dada pelo grupo que, em contrapartida, buscou uma maneira de sustentar a resposta dada. Maria, com suas intervençóes, colocou os alunos no movimento de pensar matematicamente: "Mais alguém quer comentar o que esse grupo pensou?"; "Agora vamos deixar o grupo defender sua ideia?"; "E aí, turma? O que vocês acham?"; "E o grupo, o que está achando?". Os alunos tinham o que dizer, constatamos que havia conceitos geométricos circulando. Nesses discursos orais, as significações foram sendo construídas e apropriadas pelos alunos.

A professora concluiu a análise do diálogo, apontando:

Nesse trecho, percebemos mais uma vez a importância da oralidade nas aulas de matemática. Quantos conceitos emergiram desse diálogo! Além disso, ressalto a importância das soluçôes dos alunos que não deram certo, pois se todos os grupos tivessem atingido o objetivo da tarefa, essa riquíssima discussão não teria sido possível. E o quanto que nesse momento as crianças precisam aprimorar suas formas de se pronunciar, argumentar, ajudar o outro a entender, 
(re)significar... Enfim, o quanto elas precisam FAZER matemática. (Maria, narrativa, maio 2015, grifos da autora)

A sua vivência com a professora Lia, bem como com a leitura e a discussão das narrativas das professoras no grupo possibilitou a Maria ser uma professora problematizadora em sua sala de aula. Por problematização entendemos o movimento de colocar o aluno em movimento de pensar matematicamente. Isso é perceptível no excerto dialógico e nas reflexôes apresentados anteriormente.

Ainda com o propósito de evidenciar a prática problematizadora de Maria, destacamos o excerto de uma narrativa de aula em que ela apresenta a proposta de construção dos fatos da multiplicação na tabela de dupla entrada.

Completamos a tabuada do 5, na qual os alunos julgavam fácil com os seguintes argumentos:

Ana: Porque vai $5,10,15,20 \ldots$

P: O Diogo falou que a tabuada do 5 é quase a mesma coisa que a tabuada do 10. Porque você acha isso?

Diogo: É porque ali... (aponta para a tabela) 5, 10,15, 20,25,30,35,40,45 e 50. Ena do do...

P: do 10?

Diogo: Nâo, na do 5... (vai até a lousa e aponta para a linha da tabuada do 10 e faz referência ao 50 que também aparece na tabuada do 5). É quase igual!

P: Alguém concorda com o Diogo?

Felipe: Eu concordo, porque a partir do 10, tirando o 15, é só ir acrescentando o 5.

Luiz: Prô, porque o 5 é a metade do 10. Ea do 10 é o 5 ... e o 5 é o dobro do 10.

Aluna: É! É isso mesmo!

P: Será?

Felipe: $O 5$ é o dobro?

P: Qual é o dobro de 5?

Alunos: 10 !

P: (Aponta o resultado na tabuada do 10). Qual é o dobro de 10 ?

Alunos: 20!

(Aponto o resultado na tabuada do 10 e assim sucessivamente até chegar ao dobro de 50)

P: Então, nós descobrimos que a do 10 éo dobro da tabuada do

5. Mas, e a tabuada do 5? É o que em relaçáo a do 10?

Gustavo: A metade!

P: Hum.... o 10 é o que do 20? 


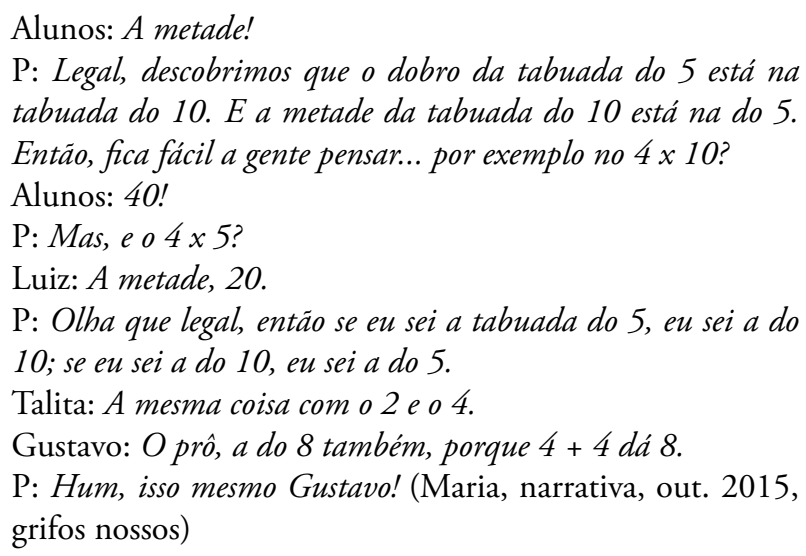

Os grifos no diálogo são nossos, com o objetivo de salientar as problematizaçóes feitas por Maria. Por meio da problematização, ela vai colocando os alunos no movimento de análise das relaçóes dobro/metade apresentados nos fatos da multiplicação. $\mathrm{E}$ as crianças vão evidenciando suas ideias e ampliando suas relaçóes. Esse é o papel mediador do professor: aquele que questiona, nomeia quando necessário, ajuda a organizar o pensamento dos alunos, não fornece respostas prontas, mas instiga-os a pensar.

Maria ressalta, ainda, no final de sua narrativa, o movimento de pensar sobre as possibilidades de encaminhamento da tarefa no decorrer dela - incluindo os processos de problematização - e as aprendizagens no processo, com seus alunos e com o grupo OBEDUC:

Nesse movimento, de pensar sobre as possibilidades de encaminhamentos da tarefa no decorrer da mesma, percebemos o quanto o processo de reflexáo do professor é constante, pois acontece no antes, durante e no depois da tarefa.

[....] Aqui, entendo o quanto o "planejar" se estende por toda a tarefa. Ele vai se modificando no processo.

Além disso, entendo que este movimento de pensar nas possibilidades e encaminhamentos da "tarefa em curso" também é o resultado de todo o meu processo de formação que, além da reflexáo da minha prática em sala de aula, se estabelece no contato com textos teóricos, com as narrativas de outras professoras, com as discussóes dos grupos que participo... Enfim, todo um contexto que me possibilita um olhar cuidadoso para os movimentos em sala de aula, de modo específico, para os movimentos da tarefa. (Maria, narrativa, ago. 2016) 
Também a professora Lia aprendeu com a pesquisadora Maria. No relatório final de 2013, ao término da parceria com Maria, Lia assim se manifestou:

O trabalho em parceria com a professora Maria possibilitou momentos muito interessantes e produtivos, foi me ajudar na sala explicando aos alunos qual era sua proposta, as crianças a receberam com muita expectativa e logo criou-se uma relação afetiva muito forte.

Aprendi muito com essa parceria, adquirindo alguns hábitos que incorporei na rotina da sala. Exemplo: antes apresentava uma situação problema e socializava as respostas corretas para refletir sobre o processo de aprendizagem, Maria mostrou que era preciso intervir mais. Exemplo: guardar os registros, retomar posteriormente para eventuais comparaçôes ou mesmo reflexóes sobre novas hipóteses que foram surgindo, analisar respostas não convencionais e opinar sobre o que não fica claro para que todos compreendam, o que poderia mudar, como os demais colegas compreendem o registro uns dos outros, quem poderia ajudar outro colega, etc. Foram momentos muito ricos, que possibilitaram à criança refletir sua prática com significado real. Essa parceria me ajudou na auto avaliação constante de minha prática docente.

Quanto à aprendizagem dos alunos, que é o mais importante, acredito que toda experiência proporcionada através do manuseio de materiais, socializaçóes, exposições de ideias e organização das mesmas (registros) são benefícios que de alguma maneira em algum momento atingiram meus alunos. Exemplo disso foi a experiência de explicar de que maneira construiu sua hipótese e aprender a compreender como os outros colegas chegaram à mesma conclusão utilizando-se de hipóteses diferentes das suas, ou seja, ficaram expostos à matemática, sentiram-se incentivados a tomar decisôes, utilizar vocabulário adequado, perceber a existência de padróes, perguntar, coletar dados e aprender a organizá-los (desenhando, escrevendo, usando símbolos, etc.). Perceber que náo existe uma maneira certa de solucionar um problema, mas sim diferentes estratégicas, ficando à vontade para tentar, ou seja, confiar em si mesmo. (Lia, relatório individual, dez. 13)

Identificamos no registro de Lia não apenas a sua aprendizagem com Maria, mas também o quanto ela se apropriou, pelo menos no discurso, dos temas que 
foram tomados como objeto de estudo e discussão no grupo: o papel do registro, o uso de materiais, a forma de organizar o trabalho em sala de aula, de escutar e valorizar o que pensam os seus alunos.

No ano de 2015, com a dissertação já concluída e defendida, Maria passou a participar do OBEDUC apenas como professora, atuando numa turma de $3^{\circ}$ ano. No segundo semestre desse ano, ela estabeleceu parceria com a mestranda Camila, que desenvolveu sua pesquisa nessa turma, tendo como objetivo observar o desenvolvimento do pensamento algébrico de alunos do $3^{\circ}$ ano. Maria analisou a primeira versão da sequência de tarefas elaborada por Camila, propôs alteraçóes e assumiu o comando da turma para o desenvolvimento das atividades.

Durante o período dessa parceria, Maria se entusiasmou e começou a produzir suas narrativas sobre o desenvolvimento do pensamento algébrico de seus alunos. Em sua última narrativa de 2015 ela revela indícios de como foi o seu processo como professora que assumiu uma postura investigativa (COCHRAN-SMITH; LYTLE, 1999) em sala de aula:

É com muita satisfação que finalizo a presente narrativa, pois reconheço os avanços que as crianças demonstraram ao longo desse semestre com relação ao pensamento algébrico. Embora considere que nossos movimentos foram apenas um primeiro passo, muitos resíduos importantes foram estabelecidos.

Quando permitimos que os alunos falem, expressem suas ideias e reflexóes, temos a possibilidade de nos aproximarmos um pouco do seu processo de significaçóes $\mathrm{e}$ isso possibilita ao professor ferramentas para fazer com que a criança avance cada vez mais. A discussão no coletivo, por sua vez, possibilita a circulação de ideias como algo crucial para os entendimentos matemáticos dos alunos.

Um ponto muito importante dos movimentos narrados refere-se às verdades provisórias apresentadas pelos alunos nos momentos de socialização e argumentação de ideias. Tais verdades são confrontadas a partir de problematizaçóes e contraexemplos apresentados pela professora e até mesmo pelos colegas. Esse movimento faz com que elas reflitam sobre suas ideias, (re) signifiquem-nas.

O registro escrito, por sua vez, se evidenciou como um instrumento que possibilitou a reflexão sobre alguns 
conceitos matemáticos, dando a oportunidade para que as significaçóes dos alunos fossem emergidas e (re) construídas num processo coletivo de construçáo do conhecimento.

Esse foi o olhar para o avanço dos meus alunos, no entanto existe o reconhecimento do meu próprio processo enquanto professora num processo constante de aprendizado. A presença e o apoio da Camila foram muito importantes para que eu pudesse ter mais segurança para trabalhar algo que era desconhecido pra mim e não fazia parte do meu planejamento. Entrar em contato com textos teóricos e narrativas também me auxiliaram muito neste processo.

Agradeço ao grupo OBEDUC pela oportunidade de aprender com o compartilhamento das práticas, com as trocas de ideias e com o processo reflexivo da minha própria prática. Eu e meus alunos fomos muito beneficiados este ano. (Maria, narrativa, nov. 2015)

Novamente, identificamos no excerto da sua narrativa o processo reflexivo que tem marcado seus textos. O que ela denomina de 'resíduos' são os conceitos apropriados pelos alunos e que são transferidos para outros contextos. Esse é um conceito de que ela se apropriou do trabalho de Hiebert et al. (1997). Para esses autores, uma boa tarefa matemática é aquela que deixa 'resíduos', ou seja, há a produção de significações pelos alunos, as quais são explicitadas em outras tarefas posteriores.

O excerto evidencia o quanto a professora tem incorporado à sua prática pedagógica suas experiências e aprendizagens estabelecidas por meio da pesquisa e das parcerias, dos grupos de discussão e estudo; e do movimento de registrar a prática pedagógica. Maria apresenta sua percepção da importância do processo de significação dos alunos como uma ferramenta que possibilita que o aluno avance, pois quando ele tem a oportunidade de manifestar suas significaçóes, por meio da problematização e da circulação de ideias, ele fornece indícios de quais são seus entendimentos matemáticos e quais as novas relaçóes necessárias para seu avanço. Ao registrar e refletir sobre o processo vivido, Maria fornece indícios de suas aprendizagens. Póe para o grupo os seus saberes da experiência, e isso nos remete a Contreras Domingo (2013, p. 132, grifos do autor):

Se trata por tanto de un saber sostenido en primera persona, que se cultiva poniendo en juego la propia 
subjetividad, la propia historia, recursos y cualidades personales, capacidades perceptivas, el propio cuerpo como presencia, los saberes "páticos" [...] Esto nos interroga acerca de las formas en que los espacios de formación del profesorado pueden constituir-se cómo procesos y experiencias de aprendizaje personal, en donde puedan emerger los saberes de la experiencia como disposición a la relación pensante con lo vivido, como trabajo de si, como "trabajo de la subjetividad (Cifali, 2012), como un "retorno sobre si” (Filloux, 1996)

Maria está constituindo sua identidade profissional nesse movimento de pesquisar, estudar, registrar sua prática, compartilhar suas narrativas no grupo e atuar junto de seus alunos. Ela se desenvolve profissionalmente como professora dos anos iniciais. Na última reunião de 2015 ela refletiu sobre a parceria estabelecida com Camila:

[...] bom foram esses momentos este ano: antes de Camila, depois de Camila [risos]. No segundo semestre eu tive o apoio dela, o que eu aprendi com a Camila eu não tinha feito nos outros anos [tarefas voltadas ao pensamento algébrico] é uma coisa nova [...] o que a Camila trouxe para mim foi tudo muito novo, e eu procurei sugar o máximo que eu pude. [...] Eu comecei com a ajuda dela e tudo se tornou mais fácil, antes eu estava sozinha e, se a gente erra, a gente erra juntas, não é, Camila? (Maria, encontro, 9 dez. 2015).

Se Maria aprendeu com Camila, esta também aprendeu com Maria:

No início, claro, foi uma insegurança tanto dela, quanto minha, eu como pesquisadora e por ser uma coisa nova. Mas foi uma parceria muito bacana, a gente conversou, teve bastante o retorno das crianças. [...] eles me procuravam tanto quanto a ela. Quanto a mim, eu aprendi muito na questão de como ela conduz a aula, como ela fez as mediaçóes das atividades, a forma como ela lidava com os problemas em sala de aula. Eu aprendi muito, ela é mais nova do que eu, mas tem mais experiência em sala de aula, tem muita situação que eu aprendi com ela, náo só o movimento com a pesquisa em si, a forma com que ela lidava com os alunos... (Camila, encontro 9 dez. 2015 ) 
Maria, durante o ano de 2016, colocou toda a ênfase no trabalho com o pensamento algébrico, produzindo narrativas e compartilhando com o grupo OBEDUC.

\section{Nossas apropriações no processo e sobre ele}

Como professoras e pesquisadoras, muito temos aprendido com o grupo e também neste momento, com o processo de análise da trajetória de Maria. Olhar para esse material, produzido ao longo desses quatro anos do projeto, e buscar por indícios de aprendizagens da pesquisadora e da professora foi também um processo de ressignificação para nós.

As leituras feitas nos possibilitaram compreender que o processo de aprendizagem docente é complexo e ocorre em diferentes situaçôes, as quais podem ou não ser apropriadas pelo professor. Ele aprende e se desenvolve com os alunos na sala de aula, principalmente quando se abre para escutá-los e acredita na capacidade deles para fazer matemática. Para isso, o diálogo, o discurso oral, é fundamental como prática de letramento - e o material de Maria aqui apresentado nos mostrou vários indícios de como ela se apropriou desses modos de trabalhar com seus alunos.

Se a aprendizagem e o desenvolvimento ocorrem nas relaçóes e nas formas de produção que afetam os sujeitos, como postula Smolka (2000), os excertos aqui apresentados nos mostram que os diferentes papéis que Maria assumiu no processo foram constituindo sua subjetividade como professora que consegue estabelecer uma relaçáo dialógica com seus alunos e com as parcerias que estabelece; tem um saber sobre como conduzir as discussóes em sala de aula, que tarefas selecionar, que materiais utilizar e como registrar - ela grava suas aulas para a produção de suas narrativas. Tais práticas foram potencializadoras desse desenvolvimento. Assim, suas práticas são historicamente construídas, dinâmicas e em constante transformação. Talvez as parcerias que estabeleceu tenham sido parte dos períodos críticos que potencializaram esse seu desenvolvimento profissional.

Maria também passou por um processo de elaboração conceitual, superando as lacunas conceituais trazidas do curso de Pedagogia: ela se arriscou ao trabalhar tarefas instigantes para o desenvolvimento do pensamento geométrico e algébrico de seus alunos. Ela se apropriou da concepção de cultura social da sala de aula de matemática, proposta por Hiebert et al. (1997), autores tomados como referência em sua pesquisa de mestrado. Ou seja, ela sabe da importância de uma boa tarefa para a elaboração conceitual matemática de seus alunos; sabe que o seu papel como professora é fundamental para criar um ambiente 
de aprendizagem; compreendeu que as ferramentas pedagógicas (o material manipulativo, o registro escrito, a oralidade) são essenciais para a produção de significaçóes matemáticas, mas o professor precisa ser o mediador e promover boas intervençóes com seus alunos.

Se Camila foi essencial para lhe apresentar boas tarefas para o desenvolvimento do pensamento algébrico, Maria, com certeza contribuiu para a formação de Camila, ao dar-lhe a conhecer e experienciar essa cultura de sala de aula de matemática.

Mas as aprendizagens foram além dessas parcerias, pois todo o grupo Obeduc tem aprendido com as práticas narradas por Maria. Ela tem nos ensinado que é possível o professor ser pesquisador da própria prática e que essa pesquisa produzida localmente, esse conhecimento que vem da prática (COCHRANSMITH; LYTLE, 1999) é um conhecimento refletido, teorizado. É um saber da experiência, mas que não pode ser confundido com vivência, é um saber que não dicotomiza a teoria e a prática, mas se constrói nas relaçôes com o outro.

\section{Referências}

ANDRÉ, Marli Eliza D. Pesquisa sobre formação de professores: tensóes e perspectivas do Campo. In: FONTOURA, Helena; SILVA, Marco. (Org.). Formaçáo de professores, culturas: desafios a $\mathrm{P} G \mathrm{G}$ em suas múltiplas dimensôes. 1. ed. Rio de Janeiro: ANPED, 2011. p. 24-36.

COCHRAN-SMITH, M.; LYTLE, S. L. Relationships of knowledge of practice: teacher learning in communities. Review of Research in Education, USA, n. 24, p.249-305, 1999.

CONTRERAS DOMINGO, José. El saber de la experiencia en la formación inicial del profesorado. Revista Interuniversitaria de Formación del Profesorado, Zaragoza, Espanha, n.78 (27,3), p. 125-136, 2013.

FREITAS, Maria Teresa de Assunção. A pesquisa de abordagem histórico-cultural: um espaço educativo de constituiçáo de sujeitos. Revista Teias - UERJ, Rio de Janeiro, v. 10, n.19, p. 1-12, 2009.

GATTI, Bernardete Angelina; BARRETTO, Elba Siqueira de Sá. (Coord.). Professores do Brasil: impasses e desafios. Brasília: UNESCO, 2009.

GATTI, Bernardete Angelina; BARRETTO, Elba Siqueira de Sá; ANDRÉ, Marli Eliza Dalmazo. Políticas docentes no Brasil: um estado da arte. Brasília: UNESCO, 2011. 
GÓES, Maria Cecília Rafael de. A abordagem microgenética na matriz históricocultural: uma perspectiva para o estudo da constituição da subjetividade. Cadernos Cedes, Campinas, ano XX, n. 50, p. 9-25, abr. 2000.

HIEBERT, James et al. Making sense: teaching and learning mathematics with understanding. Portsmouth: Heinemann, 1997.

MAYEN, Patrick. L'Appropriation des situations. In: CLOT, Yves (Dir.). Vygotski maintenant. Paris: La Dispute, 2012. p. 289-305.

NACARATO, Adair Mendes. A parceria universidade-escola: utopia ou possibilidade de formação continuada no âmbito das políticas públicas? Revista Brasileira de Educação. Rio de Janeiro. v.21, p.699 - 716, 2016.

NÓVOA, A. Professores: imagens do futuro presente. Lisboa: Educa, 2009.

ROJO, Roxane. Falando ao pé da letra: a constituição da narrativa e do letramento. São Paulo: Parábola, 2010.

SMOLKA, Ana Luíza B. O (im)próprio e o (im)pertinente na apropriação das práticas sociais. Caderno Cedes, Campinas, n. 50, p. 26-40, 2000. 